\title{
Nitrogen recycling in the apple (Malus domestica Borkh.)
}

\author{
J.S. Titus \\ Department of Horticulture, University of Illinois, Urbana, II 61801, U.S.A.
}

This paper summarizes the work of several graduate students and Research Associates with whom I have worked in recent years. Most of this work has been published, but here I attempt to integrate these results into a comprehensive scheme.

Some of this research was carried out at the University of Illinois, Urbana, Illinois, U.S.A. Other aspects were completed at University College, Dublin, Ireland.

Our early work dealt with the uptake and translocation of various forms of nitrogen by young fruit trees. While this area of nitrogen metabolism is important, the primary concern in this paper is the seasonal transformations of nitrogen in various tissues of an apple tree in which we have been engaged for the last several years.

In looking into some early literature, the recognition that the roots of the apple (Malus domestica Borkh.) could reduce nitrogen (Eckerson, 1931) and that amino acids are synthesized in apple roots (Thomas, 1927), took on new significance to us. And a report on the forms of nitrogen found in the tracheal sap of the apple was especially interesting (Bollard, 1957).

Our present concepts of nitrogen recycling in the apple began to take shape with the work of Spencer, who concentrated her research on the biochemical and enzymatic changes in apple leaf tissue during autumnal senescence. She found that one of the first indications of senescence in apple leaves was the decline in leaf protein, which began in the second week of August when day length first became less than $14 \mathrm{~h}$ (Spencer and Titus, 1972). This decline of protein was not attributed to declining RNA or DNA, since both continued to increase for an additiona) 30 days. The ability of apple leaf discs to incorporate $\left[{ }^{14} \mathrm{C}\right]$ leucine into protein was unimpaired during the time when protein was declining. We, therefore, concluded that the measured decline represented the difference between synthesis and degradation of protein. However, we had some difficulty in understanding this protein decline, since we could find only low levels of proteolytic activity during the time of protein loss. More recent work by Kang et al. (1982) demonstrated that at least 4 different proteinases are present in senescing apple leaves, as determined by their $\mathrm{pH}$ optima, substrate specificities, and their reactivities to proteinase inhibitors. An enzyme active at $\mathrm{pH}$ 4.5-5.0 appears to be a sulfhydryl-dependent (iodoacetamide and phenylmercuric acetate-sensitive) endoproteinase, and degradation of the large subunit of ribulose bisphosphate carboxylase was observed only with this 
enzyme. It is tentatively concluded that this endoproteinase is responsible for the breakdown of ribulose bisphosphate carboxylase in vivo. However, the presence of more than one endoproteinase in apple leaves is suggested by the broad range of $\mathrm{pH}$ optima of the SH-dependent enzyme. Another enzyme active at $\mathrm{pH} 6.0$ appears to be a carboxypeptidase, and was sensitive to phenylmethylsulfonylfluoride. This enzyme showed a strong hydrolytic activity against carbobenzoxyphenylalanylalanine. A sulfhydryl-dependent aminopeptidase and a second hydroxyl-dependent carboxypeptidase were active at $\mathrm{pH} 7.5$.

Total autolytic activity (the sulfhydryldependent endoproteinase), as measured by the disappearance of proteins, decreased during the period of protein decline. Evidence is presented that the measured proteinase activity can be dependent upon assay methods and substrates. While the disappearance of protein measures most endo-type activity, the ninhydrin assay appears to measure exotype activity preferentially.

When day length decreased to less than $12 \mathrm{~h}$ in late September, the activities of RNase (EC 3.1.27.1), polyphenol oxidase (EC 1.10.3.1) and malate dehydrogenase (EC 1.1.1.37) increased dramatically, and chlorophyll, DNA and RNA began to decline. Free amino acids in the leaf petioles were measured during this period of dramatic change. However, the pattern was not very consistent, as the amino acids apparently continued to move out through the petiole and did not accumulate until after the first killing frost in early November.

K.K. Shim and coworkers, taking advantage of earlier work in Denmark (Oland, 1960) and with our interest in the changes apple leaves undergo during senescence (Spencer and Titus, 1972), carried out some detailed work on urea metabolism of senescing apple leaves (Shim et al.,
1972). They found that these leaves absorbed $80 \%$ of the applied urea in $48 \mathrm{~h}$ with greater absorption in light than in darkness. The amount of urea absorbed paralleled the increase in soluble nitrogen, the bulk of which was urea. The changes in total soluble nitrogen paralleled the changes in urea nitrogen. During leaf senescence, chlorophyll, total nitrogen and protein declined and much of this nitrogen was translocated to storage tissues. Trees which received a post-harvest urea spray produced a significantly greater amount of shoot growth and fruit set of apples than trees receiving no urea or soil application of urea. The yield was not significantly different between treatments. However, the efficiency of nitrogen utilization by a $5 \%$ urea spray was 4 -fold greater than the soil application of urea.

Shim et al. (1973) made a study of the urease (EC 3.5.1.5) activity of various tissues of the apple. They found urease to be present in leaves, roots and bark with actively growing tissues containing higher activity than senescing tissues. The activity in the leaves declined steadily during leaf senescence, but abscised leaves still contained about half of their initial activity. In the bark, the urease activity changed very slightly. Urease activities of leaves and bark were always greater in those trees which had received an application of urea. In senescing apple leaves, urea induced a rapid increase in urease activity. The changes in total activity and specific activity of urease were parallel, suggesting that urease was synthesized de novo. The enzyme was inhibited by low concentrations of ammonia and this inhibition suggests product inhibition. The presence of urease activity in such diverse tissues of the apple, such as roots, bark and leaves, is especially important at the present time, as urea is becoming such a common form of nitrogen applied to both the soil and foliar sprays in apple orchards. 
The preceding has dealt with events occurring in the growing season, during senescence and the immediate postsenescent season. We then became interested in changes in nitrogen storage in wood and bark and the urea effect on these changes during the dormant season and early spring growth stages.

O'Kennedy and Hennerty, working with the author in Ireland, initiated such a study with Golden Delicious apple trees, comparing tissue extracts from trees which had received post-harvest urea sprays with unsprayed trees and trees which had received ground applications of urea (O'Kennedy et al., 1975a, b). They found that the application of urea sprays in October increased the amounts of nitrogen translocated from leaves into storage tissues. Consequently, the sprayed trees had significantly higher levels of total nitrogen, especially in the bark. This increase was due mainly to an increase in protein nitrogen in January. In February, the soluble nitrogen increased, while the protein remained unchanged. On the other hand, there were no significant differences between treatments in wood total nitrogen levels in January. In the sprayed trees, however, there was an increase in total wood nitrogen from January due to an increase in soluble nitrogen, suggesting a redistribution effect.

The proteins, as a primary reserve of nitrogen in both bark and wood, were hydrolyzed in March (shortly before shoot growth resumed) and resulted in a rapid increase in the soluble nitrogen for use in the new growth. Prior to the hydrolysis of protein, there appeared to be a significant amount of soluble nitrogen present, especially in the wood. Arginine composed $8-17 \%$ of the total free amino acid in bark and $20-30 \%$ in wood.

Later, O'Kennedy joined our laboratory in Illinois and conducted a more detailed study of the proteins in bark of the apple in the dormant condition and in the early stages of regrowth (O'Kennedy and Titus, 1979). Most of these experiments were performed using mist-propagated $1 \mathrm{yr}$ old rooted cuttings of Malling Merton 106 rootstocks. The techniques of column chromatography, electrophoresis and gas chromatography were applied.

From O'Kennedy's work, we developed a working definition of the storage proteins in the bark using 2 criteria: they must be predominant and they must disappear as growth resumes.

In this study, O'Kennedy separated total protein into 3 groups of proteins using diethylaminoethyl (DEAE)-cellulose chromatography. The protein fractions were eluted from the column using a stepwise gradient of $0.1,0.2$ and $0.3 \mathrm{M} \mathrm{NaCl}$ and were designated as peaks I, II and III proteins. The elution patterns of proteins in peak I and II corresponded closely with those of neutral sugars, indicating that these proteins were glycoproteins. No neutral sugars were found in the fractions collected in peak III. The acid hydrolysates of the peak III proteins were characterized by their high arginine content comprising $24 \%$ of the total amino acid nitrogen. This contrasted with 5 and $9 \%$ for peaks I and II, respectively. In subsequent work, Kang and Titus (1987) examined a possible relationship between soluble proteins and resistance to cold injury of the apple $\mathrm{cr}$ Golden Delicious. Shoot samples, collected from the orchard during autumnal senescence, were exposed to -20 and $-40^{\circ} \mathrm{C}$ for a $4 \mathrm{~h}$ test period. Visual examination of the inner bark and outer wood was made $20 \mathrm{~h}$ after exposure to these temperatures. Flesults indicated that there was a 2 stage development of cold acclimation in apple shoots with regard to the increase in proteins. It was found that the 1st stage of acclimation to $-20^{\circ} \mathrm{C}$ was correlated more with total soluble proteins, whereas the 2 nd stage to $-40^{\circ} \mathrm{C}$ was cor- 
related more with a specific group of proteins (peak III) separated by DEAE-cellulose column chromatography.

When dormant apple trees were placed in growth chambers at 20,25 and $30^{\circ} \mathrm{C}$ for 14 days and the protein content of the bark was measured at $48 \mathrm{~h}$ intervals, the protein loss was found to be very temperature-dependent. At $20^{\circ} \mathrm{C}$, protein loss was not dramatic until between days 10 and 12 , while at $30^{\circ} \mathrm{C}$ protein loss was apparent between days 2 and 4 .

At the time O'Kennedy was concluding his research in our laboratory, we had a generalized understanding of some major changes in several classes of nitrogenous constituents in apple leaves under orchard conditions (Spencer and Titus, 1972) as well as some major changes in nitrogenous compounds extracted from bark tissue during late dormancy and early growth under controlled environmental conditions. However, we had not looked at simultaneous changes taking place in both leaf and bark tissues from the middle of the growing season through mid-dormancy.

When S.M. Kang joined our laboratory, this was a natural challenge. We collected samples from our experimental planting of Golden Delicious apple trees biweekly from July to December, and followed the quantitative and qualitative changes in proteins and ethanol-soluble nitrogenous constituents throughout that period (Kang and Titus, 1980b). The results indicated that, while senescing leaves lost $46 \%$ of their proteins, total bark protein increased $240 \%$ during senescence. However, the protein nitrogen gain in bark tissue was about the same as the protein nitrogen loss in leaf tissue per unit fresh weight of these tissues. This was a significant finding, since it was additional evidence that apple bark tissue served as a metabolic sink for those proteins degraded and exported from senescing leaves. The pattern of bark protein accumulation ap- peared to be gradual from early August to late November and was sequential from lower to higher molecular weight species of proteins. The final electrophoretic profile of total bark proteins was established at the later stages of senescence. By late November, $89 \%$ of the nitrogen in the bark tissue was found in proteins with $11 \%$ in the ethanol-soluble fractions. Fractionation of the total bark proteins by DEAE-cellulose chromatography indicated that the final upsurge of bark proteins observed in November was associated primarily with those proteins in peak III.

The changes in nitrogenous compounds, which function as storage forms of nitrogen, undoubtedly require extensive enzyme-catalyzed reactions, since most of the nitrogen in leaf and bark tissue is present as proteins, while translocation is in the form of amino acids. And because glutamine and glutamate play a central role in amino acid metabolism and the amides are of special importance in storage and translocation of nitrogenous compounds in higher plants, we studied the seasonal changes in glutamine synthetase (GS) (EC 6.3.1.2), glutamate synthase (GOGAT) (EC 2.6.1.53) and glutamate dehydrogenase (GDH) (EC 1.4.1.4) in both leaf and bark tissues of Golden Delicious apple trees (Kang and Titus, 1980c). From the measured enzyme activities, we attempted to estimate the in vivo catalytic potentials of the enzymes with special reference to nitrogen mobilization and conservation of senescing apple trees. From this study, we concluded that the physiological role of GS in senescing leaves is to furnish the amide(s) prior to mobilization of nitrogen to the storage tissue. Together with GDH, another important role of leaf GS would be the incorporation of ammonia into organic compounds. On the other hand, the higher activity of GOGAT in bark tissue could provide a mechanism to transform the im- 
ported amide nitrogen to $\alpha$-amino nitrogen of glutamate or storage protein synthesis. Additional detailed studies on GS and GOGAT from apple leaves and bark have been made. Their kinetics, cofactor dependence, $\mathrm{pH}$ optima and their regulation have been established (Kang and Titus, 1981a, b).

Previous reference has been made to protein breakdown in apple leaves. As a whole, the breakdown of protein is important in 2 distinct stages of nitrogen recycling in the apple. During senescence, leaf proteins are hydrolyzed to amino acids as indicated earlier. And during late dormancy, there is a marked breakdown in apple bark proteins which O'Kennedy noted. These processes are believed to be enzymatically catalyzed, but are complicated. In the first place, we are dealing with more complex proteins in the bark of apple trees. This contrasts with simpler systems, such as pumpkin seeds, in which proteolysis has been studied by many workers (Spencer et al., 1975).

S.M. Kang made a serious attempt to look at proteolytic activity of apple bark (Kang and Titus, 1980a). He succeeded in isolating a major protease present in dormant bark tissue of Golden Delicious apple shoots by using affinity chromatographic techniques. This protease was partially purified by hemoglobin-coupled Sepharose column chromatography. This was the first time we were able to separate a proteolytic enzyme from its substrate complex. This protease was active at $\mathrm{pH} 4.6$ and at temperatures ranging from $30-50^{\circ} \mathrm{C}$ and was found to be sulfhydryl-dependent. Substrate specificity and the separation of the reaction products indicated that the enzyme is likely to be an endoprotease. We concluded from this work that storage proteins in apple bark tissue undergo some modification prior to their eventual hydrolysis to amino acids, which requires a multi-enzyme sys- tem(s). The results also indicated that the activation of the sulfhydryl-dependent acid endoprotease is associated with the rapid metabolism of storage proteins which accompanies bud break upon regrowth.

As the trees start growing in the spring or are exposed to warm temperatures as discussed earlier, the bark tissue undergoes both quantitative and qualitative changes in nitrogenous compounds. The soluble proteins in bark tissue declined dramatically, while amino acids increased up to the period of bud swelling. In vitro activities of an acid endoprotease and autolysis increased upon regrowth, followed by a sharp decline at the later stages of spring growth. It appeared that in vivo breakdown of proteins in the tissue is very selective. The majority of proteins showed little evidence of net breakdown during early growth, although low molecular mass proteins declined and later accumulated. Two polypeptides of 38000 and $56000 \mathrm{Da}$ disappeared later in the growth period. However, the $60 \%$ decline in total protein in the bark during spring growth could not be accounted for by the loss of these 2 specific proteins (S.M. Kang, K.C. Ko and J.S. Titus, unpublished results).

When we put all the information discussed so far together, the annual cyclic fashion of nitrogen transformations in the apple can be summarized in 3 steps: 1) nitrogen is mobilized from senescing leaves to the storage tissues, especially in the bark; 2) nitrogen is conserved as proteins and the storage protein undergoes little modification during the dormant period; and 3) nitrogen is re-utilized through storage protein hydrolysis to supply nitrogen for developing tissues.

In order for this cyclic transformation of nitrogenous compounds to be made possible, there must be some essential enzyme systems catalyzing such transformations. Both senescing leaves and bark 
tissue contain proteolytic enzymes whose nature and regulation are very much unknown. The fact that the amides and arginine are of special importance in storage and translocation of nitrogen requires extensive enzyme-catalyzed reactions among nitrogenous compounds. Data have been accumulated that the use of post-harvest sprays of urea brings about substantial changes in the nitrogen status of the storage tissues.

It should be emphasized at this point that the replenishment of nitrogen by root uptake has never been ignored. The quantitative contribution of nitrogen taken up by roots may be more important than that recycled as such from senescing leaves. However, the nitrogen absorbed by the roots may not be available for early spring growth and for increasing the percent of flowers which set fruit.

\section{References}

Bollard E.G. (1957) Composition of nitrogen fraction of apple tracheal sap. Aust. J. Biol. Sci. 10, 279-287

Eckerson S.H. (1931) Seasonal distribution of reductase in various organs of an apple tree. Contrib. Boyce Thompson Inst. 3, 405-412

Kang S.M. \& Titus J.S. (1980a) Isolation and partial characterization of an acid endoprotease present in dormant apple shoot bark. Plant Physiol. 66, 984-989

Kang S.M. \& Titus J.S. (1980b) Qualitative and quantitative changes in nitrogenous compounds in senescing leaf and bark tissues of the apple. Physiol. Plant. 50, 285-290

Kang S.M. \& Titus J.S. (1980c) Activity profiles of enzymes involved in glutamine and glutamate metabolism in the apple during autumnal senescence. Physiol. Plant. 50, 291-297
Kang S.M. \& Titus J.S. (1981a) Characterization of glutamine synthetase in the apple. Physiol. Plant. 53, 239-244

Kang S.M. \& Titus J.S. (1981b) Isolation and characterization of glutamate synthase in the apple. J. Am. Soc. Hortic. Sci. 106, 765-768

Kang S.M. \& Titus J.S. (1987) Specific proteins may determine maximum cold resistance in apple shoots. J. Hortic. Sci. 62, 279-283

Kang S.M., Matsui H. \& Titus J.S. (1982) Characteristics and activity changes of proteolytic enzymes in apple leaves during autumnal senescence. Plant Physiol. 70, 1367-1372

O'Kennedy B.T. \& Titus J.S. (1979) Isolation and mobilization of storage proteins from apple shoot bark. Physiol. Plant. 45, 419-424

O'Kennedy B.T., Hennerty M.J. \& Titus J.S. (1975a) Changes in the nitrogen reserves of apple shoots during the dormant season. $J$. Hortic. Sci. 50, 321-329

O'Kennedy B.T., Hennerty M.J. \& Titus J.S. (1975b) The effects of autumn foliar sprays of urea on storage forms of nitrogen extracted from bark and wood of apple shoots. J. Hortic. Sci. $50,331-338$

Olan K. (1960) Nitrogen feeding of apple trees by post-harvest urea sprays. Nature 185,857

Shim K.K., Titus J.S. \& Splittstoesser W.E. (1972) The utilization of post-harvest urea sprays by senescing apple leaves. J. Am. Soc. Hortic. Sci. 97, 592-596

Shim K.K., Splittstoesser W.E. \& Titus J.S. (1973) Changes in urease activity in apple trees as related to urea applications. Physiol. Plant. 28, 327-333

Spencer P.W. \& Titus J.S. (1972) Biochemical and enzymatic changes in apple leaf tissue during autumnal senescence. Plant Physiol. 49, 746-750

Spencer P.W., Titus J.S. \& Spencer R.D. (1975) Direct fluorometric assay for proteolytic activity against intact proteins. Anal. Biochem. 64, 556566

Thomas W. (1927) The seat of formatiosn of amino acids in Pyrus malus L. Science 66, 115117 